\title{
Stability and change of body mass index as a predictor of disability
}

\author{
Ropponen, Annina
}

2016-01-19

Ropponen , A , Silventoinen , K T , Koskenvuo , M J , Svedberg , P \& Kaprio , J A 2016 , '

Stability and change of body mass index as a predictor of disability ' , Scandinavian Journal of Public Health , vol. 44 , no. 4 , pp. 369-376 . https://doi.org/10.1177/1403494815622849

http://hdl.handle.net/10138/223872

https://doi.org/10.1177/1403494815622849

publishedVersion

Downloaded from Helda, University of Helsinki institutional repository.

This is an electronic reprint of the original article.

This reprint may differ from the original in pagination and typographic detail.

Please cite the original version. 


\title{
Stability and change of body mass index as a predictor of disability pension
}

\author{
ANNINA ROPPONEN ${ }^{1}$, KARRI SILVENTOINEN ${ }^{2}$, MARKKU KOSKENVUO $^{3}$, \\ PIA SVEDBERG ${ }^{4} \&$ JAAKKO KAPRIO ${ }^{3,5,6}$
}

${ }^{1}$ Finnish Institute of Occupational Health, Helsinki, Finland, 2Population Research Unit, Department of Sociology, University of Helsinki, Finland, ${ }^{3}$ Department of Public Health, University of Helsinki, Finland, ${ }^{4}$ Division of Insurance Medicine, Department of Clinical Neuroscience, Karolinska Institutet, Sweden, ${ }^{5}$ Department of Mental Health and Substance Abuse Services, National Institute for Health and Welfare, Finland, and ${ }^{6}$ Institute for Molecular Medicine, University of Helsinki, Finland

\begin{abstract}
Aims: To investigate whether stability or change in body mass index (BMI) predict disability pension (DP) due to musculoskeletal diagnosis (MSD) when controlling for familial confounding. Methods: Our study cohort consisted of 17,169 Finnish twins born before 1958. Data on BMI and multiple covariates from questionnaires in 1975 and 1981 were included and DPs were collected from the national pension registers until the end of 2004. Cox proportional hazards regression models with Hazard Ratios (HR) and 95\% Confidence Intervals (CI) were used for statistical analyses. Results: General DP was granted to 2853 individuals and DP due to MSD to 1143 individuals during the 23-year follow-up. A oneunit increase in BMI in both 1975 (HR 1.08, 95\% CI 1.05, 1.10) and 1981 (HR 1.06, 95\% CI 1.04, 1.07), as well as the stability of and change in BMI from 1975 to 1981 were all associated with an increased risk of DP. These associations held in the analyses controlling for multiple covariates (age, sex, socioeconomic status, education, marital status, leisure-time physical activity, and musculoskeletal pain), and mainly also familial confounding, that is, genetics and shared environment. HR for stable obesity was 2.28 (95\% CI 1.69, 3.08) for DP due to MSD, and $1.91(95 \%$ CI $1.56,2.34)$ for general DP in the fully adjusted models. Conclusions: BMI is an early predictor of general DP and also of DP due to MSD. Owing to the independency of various covariates and potentially also familial confounding, BMI may possibly have a direct effect on the risk of DP.
\end{abstract}

Key Words: Sickness absence, disability pension, musculoskeletal disorders, body mass index, prospective design

\section{Background}

Permanent incapacity to work carries a burden at both the societal and individual level. In many countries, people with permanent incapacity to work are granted a disability pension (DP) to compensate for decreased income. Many diseases and accidents may give rise to permanently decreased work capacity, for which reason a medical certificate is commonly required before a DP is granted. However, societal, work, and individual characteristics may enhance or diminish the impact of the disease or accident, and these are often considered when making the decision to grant a DP. One such characteristic is relative weight, which at its extreme is manifested as obesity. Obesity, which may even increase [1], is furthermore associated with the occurrence and severity of many chronic diseases [2] that are behind the granting of DPs and, therefore, cause both direct and indirect costs to society [3]. Even in the absence of concomitant diseases, severe obesity can impede work capacity. Obesity by itself can result in stigmatization at workplaces, thus contributing to a diminished work capacity.

Correspondence: Annina Ropponen, Finnish Institute of Occupational Health, Topeliuksenkatu 41 a A, 00250 Helsinki, Finland. E-mail: annina. ropponen@ttl.fi

(Accepted 24 November 2015)

(C) 2016 the Nordic Societies of Public Health

DOI: $10.1177 / 1403494815622849$ 
Epidemiological studies of DP, either as diagnosis-specific or in general, have suggested that relative weight, commonly assessed as body mass index (weight per height squared, BMI) plays a role in the process of becoming incapable of working [4-10]. However, most of these studies, even a study based on partially the same data from the Finnish Twin Cohort, have investigated BMI at one time point only, i.e. ignoring the potential change or stability of relative weight $[6,7,9-11]$. Furthermore, if the change in or stability of BMI has been investigated, the evaluations have been limited to comparisons between decrease and increase vs. stability. Examples of this include a study of Swedish twins with two time points, 25 years apart, preceding six years follow-up and another study of the Finnish working-age population with two time points, 5 years apart $[5,12]$, a study with focus on temporary work incapacity in terms of sickness absence spells [12], or a study focused only on obesity, such as a very large study of over one million Swedish military conscripts [13]. Hence, there is a need to take a closer look at the relationship between BMI and work incapacity, and BMI's contribution to the risk of DP.

A fact that needs to be taken into account is genetics, which is known to influence both BMI [14] and DP [15-17]. Therefore, it is possible that observed associations between BMI and DP are confounded by genetic or shared environmental (likely related to family background and childhood) influences, as suggested by an earlier study partially based on the same dataset [11], and a study of Swedish twins [5]. A strong method for controlling these influences are within-family comparisons, especially the co-twin control method that compares twin pairs who are discordant in the factors of interest (in this case BMI and DP). The co-twin control method also extends the case-control design, as the same-sex twins are matched in genetic background (totally in the case of monozygotic (MZ) pairs, and partially in the cases of dizygotic (DZ) pairs), parental characteristics, most childhood experiences and exposures, and have perfect matching age. Therefore, the co-twin control design is particularly useful, as it provides strong evidence of possible causal associations, compared with observational epidemiological studies of unrelated individuals. While studying discordant twin pairs, no association is expected between BMI and DP if genetics and shared environmental influences (i.e. familial factors) are of importance. Instead, if results of discordant twin pairs are similar to the results within the whole cohort (i.e. between all individuals) then factors specific to each individual are more important. The latter finding would support a causal association.
The aim of this study was to investigate whether stability or change in BMI predict DP due to musculoskeletal diagnosis (MSD), to evaluate if an association exists with DP in general, and to control whether familial confounding has an influence on these associations.

\section{Methods}

The baseline questionnaire of the Finnish Twin Cohort includes data from a comprehensive set of questions on sociodemographic, health, and lifestyle factors mailed in 1975 to all same-sex Finnish twins born between 1880 and 1957, and to both co-twins who were still alive (response rate $89 \%$ ) $[10,18]$. In 1981 , the same twins were mailed a follow-up questionnaire irrespective of whether they had responded to the baseline questionnaire (response rate $84 \%$ ). A total of 24,043 twin individuals born between 1910 and 1957 were available for this study. For the analyses, only the twin individuals who responded to both questionnaires with information on BMI, had not retired from work before the date of the 1981 questionnaire, and were resident in Finland in 1981 were included. Hence, the final study sample comprised 17,169 twin individuals ( $52 \%$ women), including 2259 complete $\mathrm{MZ}$ pairs, 4545 complete $\mathrm{DZ}$ pairs, and 3561 twin individuals whose co-twin did not fulfill the selection criteria.

Data regarding DP was obtained from the official Finnish pension registers [15]. In the Finnish pension system, a medically confirmed illness, disease, or injury which essentially restricts or prevents working is a requirement for a disease-based early retirement pension (DP or individual early retirement pension for employees aged 58-64) to be granted. However, as part of the evaluation of work capacity, functional capacity, occupational skills, education, work tasks, and work history are always assessed. The insurance institutions make the final decision regarding a person's work incapacity. For this study, DP in general, and DP due to MSD was selected on the basis of the International Classification of Diseases (ICD) ICD10 codes M00-M99, and the corresponding codes in ICD-8 and ICD-9, as encoded by the Finnish insurance institutions.

Information on mortality and migration were used for the assessment of censoring the data derived from the Population Register Centre of Finland. Unique personal identification codes, which are assigned to all Finnish residents, were used for the record linkages. The follow-up time was from the date of the 1981 questionnaire to the date when DP was awarded, until the person began to receive an old age pension, to the date of death/emigration, or to 31 December 2004, whichever occurred first. 
BMI $\left(\mathrm{kg} / \mathrm{m}^{2}\right)$ was computed from self-reported weight and height; the validity of self-reported BMI values in this cohort was found to be high [19]. First, BMI was analyzed as a continuous trait in 1975 and 1981 in the regression models. Then the change between 1975 and 1981 was assessed by including BMI in 1975 and BMI in 1981 in the same model to reflect on BMI level and change. For descriptive purposes, and to reflect the change between 1975 and 1981, the WHO classification was used. Based on this, BMI was categorized into < 18.5 (underweight), 18.5-25 (normal weight), 25-30 (overweight), and $>30$ (obesity). The stability of and change in BMI was assessed using combinations of five categories: stable normal weight (reference); stable overweight; stable obesity; decreased BMI (any change from 1975 to a lesser BMI category in 1981); and increased BMI (any change from 1975 to a higher BMI category in 1981), including only those with full BMI data at both time points and who were eligible for follow-up. The number of individuals with stable underweight (underweight both in 1975 and 1981) was so low $(<6 \%)$ that they were omitted from the analyses.

In this study, the covariates included from the 1975 questionnaire were age, sex, and socioeconomic status based on occupation. From the 1981 questionnaire, we included: education (nine categories by years of education, converted into years of education); marital status (dichotomized to those living with someone vs. single); estimates of leisure-time physical activity measured by monthly frequency, mean duration, and mean intensity, and computed to metabolic equivalent (MET) values [20]; and musculoskeletal pain assessed by the incidence of pain in the lower back, neck or shoulder area that had affected work capacity in recent years (yes vs. no). The responses to these three musculoskeletal pain items were used to calculate a summary pain score (0-3 locations) [11].

\section{Statistical analysis}

All the analyses were performed using version 12.1 of the Stata statistical software. DP and DP due to MSD as the outcome variables were used to calculate Cox proportional HRs with $95 \%$ CIs using the follow-up time in days. Due to dependent observations in the sample - i.e. sampling twin pairs instead of unrelated individuals - pair identity was used to cluster all the analyses in order to adjust the standard errors for a lack of statistical independence within pairs [21]. In all models with the whole cohort, age was included as a continuous variable, and sex was stratified to provide men and women with their own baseline hazards to control for the effects of sex. The proportional hazard assumptions were tested by Schoenfeld residuals for BMI in 1975 and BMI in 1981 in separate models accounting for age and sex. No violations were detected.

First, we conducted basic models accounting for age and sex. In order to illustrate the linear trend in BMI in 1975 and 1981, we calculated the HRs with 95\% CIs for both DP and DP due to MSD, adjusting for age and stratifying with sex for each value within each respective year's BMI, and presented the information in a graph. Due to the low numbers of individuals scoring the highest and lowest values of BMI, values below $18 \mathrm{~kg} / \mathrm{m}^{2}$ were collapsed into a single value of $18 \mathrm{~kg} / \mathrm{m}^{2}$, and values ranging from 32 $\mathrm{kg} / \mathrm{m}^{2}$ to $47 \mathrm{~kg} / \mathrm{m}^{2}$ were collapsed into $32 \mathrm{~kg} / \mathrm{m}^{2}$. The reference group for the linear trend evaluation was set to the mean value, this being a value of $22 \mathrm{~kg} / \mathrm{m}^{2}$ for $\mathrm{BMI}$ in 1975, and a value of $23 \mathrm{~kg} / \mathrm{m}^{2}$ for $\mathrm{BMI}$ in 1981.

Next, we calculated separate models for DP and DP due to MSD, with all the covariates included in the models. The selection of covariates was due to their significance in the prediction of DP, some of which were based on earlier studies of partially the same cohort $[9,11]$, but also due to their potential association with BMI.

The third set of analyses included twin pairs discordant for DP or DP due to MSD, applying conditional Cox proportional hazards models [22]. In these conditional models, the follow-up time to DP was analyzed in relation to the follow-up time of the co-twin. This means that one twin had a DP during the follow-up but that his/her co-twin had not been granted DP. The effects of potentially confounding familial factors can be controlled in the models when twin pairs are stratified, hence, allowing each twin pair to have their own baseline hazard. The number of discordant pairs for DP was $398 \mathrm{MZ}$ and $1075 \mathrm{DZ}$ pairs, whereas for DP due to MSD, it was $164 \mathrm{MZ}$ and $516 \mathrm{DZ}$ pairs. By using BMI as a continuous trait, we maximized the information from the available discordant pairs.

Finally, we tested the interaction between BMI and age separately for men and women, but also the interaction between BMI and sex while accounting for age. The interaction term was added to the models and the statistical significance of the interaction term was tested by the log-likelihood ratio test.

\section{Results}

Table I presents the baseline descriptive information regarding those granted DP or DP due to MSD, and those without DP during the follow-up. The mean BMI was slightly higher among men than women, 
Table I. Frequencies and percentages of background factors and BMI categories for DP due to MSD, general DP (also including MSD), and no DP with complete BMI data from 1975 to 1981 and eligible for follow-up (1981-2004).

\begin{tabular}{|c|c|c|c|c|c|c|c|c|c|c|c|c|}
\hline & \multicolumn{4}{|c|}{ DP due to MSD $(n=1143)$} & \multicolumn{4}{|c|}{ DP in general $(n=2853)$} & \multicolumn{4}{|c|}{ No DP $(n=14,316)$} \\
\hline & \multicolumn{2}{|l|}{ Men } & \multicolumn{2}{|c|}{ Women } & \multicolumn{2}{|l|}{ Men } & \multicolumn{2}{|c|}{ Women } & \multicolumn{2}{|l|}{ Men } & \multicolumn{2}{|c|}{ Women } \\
\hline & Mean & SD & Mean & SD & Mean & SD & Mean & SD & Mean & $\mathrm{SD}$ & Mean & $\mathrm{SD}$ \\
\hline Age at baseline (1975) & 37.1 & 8.8 & 37.8 & 8.2 & 35.8 & 8.9 & 35.3 & 9.0 & 29.8 & 9.5 & 29.9 & 10.2 \\
\hline Education years $(1975)$ & 6.4 & 1.6 & 6.7 & 1.7 & 6.7 & 2.7 & 7.1 & 2.1 & 8.0 & 3.3 & 8.4 & 3.2 \\
\hline Leisure-time physical activity (MET) & 4.5 & 4.4 & 4.1 & 3.5 & 4.2 & 4.0 & 4.1 & 3.5 & 4.6 & 4.4 & 4.1 & 3.5 \\
\hline BMI 1975 & 25.0 & 2.9 & 24.0 & 3.4 & 24.8 & 3.1 & 23.3 & 3.5 & 23.3 & 2.8 & 21.8 & 3.0 \\
\hline BMI 1981 & 25.6 & 3.0 & 24.7 & 3.8 & 25.5 & 3.1 & 24.1 & 3.8 & 24.1 & 2.8 & 22.5 & 3.3 \\
\hline Socioeconomic status & & $\%$ & & $\%$ & & $\%$ & & $\%$ & & $\%$ & & $\%$ \\
\hline Upper white collar & & 3 & & 2 & & 7 & & 2 & & 11 & & 5 \\
\hline Lower white collar & & 20 & & 24 & & 22 & & 28 & & 21 & & 35 \\
\hline Skilled worker & & 54 & & 39 & & 50 & & 37 & & 42 & & 29 \\
\hline Unskilled worker & & 13 & & 18 & & 11 & & 16 & & 9 & & 11 \\
\hline Farmer & & 10 & & 14 & & 8 & & 12 & & 8 & & 6 \\
\hline Other & & 0 & & 3 & & 1 & & 5 & & 10 & & 14 \\
\hline Musculoskeletal pain & & 64 & & 62 & & 56 & & 58 & & 36 & & 36 \\
\hline Married & & 80 & & 74 & & 77 & & 70 & & 73 & & 71 \\
\hline \multicolumn{13}{|l|}{ BMI 1975} \\
\hline$<18.5$ & & 0 & & 3 & & 1 & & 4 & & 2 & & 10 \\
\hline $18.51-24.9$ & & 54 & & 63 & & 55 & & 69 & & 74 & & 77 \\
\hline $25-29.9$ & & 39 & & 28 & & 38 & & 22 & & 22 & & 12 \\
\hline$\geqslant 30$ & & 7 & & 6 & & 6 & & 5 & & 2 & & 2 \\
\hline \multicolumn{13}{|l|}{ BMI 1981} \\
\hline$<18.5$ & & - & & 2 & & 0 & & 2 & & 1 & & 6 \\
\hline $18.51-24.9$ & & 45 & & 55 & & 47 & & 62 & & 65 & & 75 \\
\hline $25-29.9$ & & 46 & & 35 & & 45 & & 28 & & 31 & & 16 \\
\hline$\geqslant 30$ & & 9 & & 9 & & 8 & & 7 & & 3 & & 3 \\
\hline \multicolumn{13}{|l|}{$1975-1981$} \\
\hline Stable normal weight & & 40 & & 50 & & 42 & & 57 & & 61 & & 68 \\
\hline Stable overweight & & 31 & & 22 & & 30 & & 16 & & 18 & & 8 \\
\hline Stable obesity & & 5 & & 5 & & 4 & & 4 & & 1 & & 1 \\
\hline Decreased weight category & & 7 & & 6 & & 6 & & 7 & & 5 & & 8 \\
\hline Increase in weight category & & 18 & & 16 & & 17 & & 15 & & 15 & & 11 \\
\hline
\end{tabular}

but also among those granted DP or DP due to MSD than among those with no DP in both 1975 and 1981 (Table I). The proportion of those maintaining stable normal weight (from 1975 to 1981 ) was $60-68 \%$ among those without DP, and $40-57 \%$ among those with DP or DP due to MSD.

Each one-unit increase in BMI in both 1975 and 1981 was significantly associated with an increased risk of DP and DP due to MSD (Table II). The linear trends for the HR with 95\% CI for each value of BMI in 1975 and 1981 are shown in Figure 1 for DP, and in Figure 2 for DP due to MSD. These associations were also evident when marital status, education, socioeconomic status, leisure-time physical activity, and musculoskeletal pain locations were accounted for in the analyses, but also in the analyses that mutually adjusted the BMI in 1975 and 1981 (models 2-3, Table II). The analyses of the effect of a one-unit increase in BMI among discordant twin pairs (models $4-6$, Table II) indicated independence from familial confounding, although the slightly attenuated point estimates in $\mathrm{MZ}$ twins suggest that the possibility of familial confounding cannot be fully ruled out.

The stability of and change in BMI from 1975 to 1981 indicated an elevated risk of both DP and DP due to MSD for all BMI categories when compared to those with stable normal weight (Table III). The association remained in the analyses when covariates were accounted for, but in the models accounting for familial confounding, the point estimates attenuated slightly in $M Z$ twins.

Interaction between $\mathrm{BMI}$ and sex was not significant for DP or DP due to MSD when age was adjusted for. BMI and age showed no significant interaction for DP, but among women, the interaction was significant for DP due to MSD $(p=.009)$, whereas among men it was not. The effect of BMI on DP risk was lower among younger than older women. 
Table II. Cox proportional hazard ratios with 95\% CI for each unit increase in BMI in 1975 and 1981 for those granted DP or DP due to MSD during the 23-year follow-up (1981-2004).

\begin{tabular}{|c|c|c|c|c|}
\hline & \multicolumn{2}{|c|}{ DP due to MSD } & \multicolumn{2}{|l|}{ DP } \\
\hline & HR & $95 \% \mathrm{CI}$ & HR & $95 \%$ CI \\
\hline \multicolumn{5}{|l|}{ BMI in 1975} \\
\hline Model 1: All individuals, age and sex adjusted & 1.10 & $1.08,1.12$ & 1.08 & $1.06,1.09$ \\
\hline Model 2: All individuals, full covariate adjustment & 1.08 & $1.05,1.10$ & 1.06 & $1.04,1.07$ \\
\hline Model 3: All individuals, BMI in 1981, age and sex adjusted & 1.05 & $1.01,1.09$ & 1.04 & $1.01,1.07$ \\
\hline Model 4: All pairs & 1.03 & $0.98,1.09$ & 1.04 & $1.00,1.07$ \\
\hline Model 5: DZ pairs & 1.05 & $0.99,1.11$ & 1.04 & $1.01,1.08$ \\
\hline Model 6: MZ pairs & 0.97 & $0.86,1.09$ & 0.99 & $0.92,1.08$ \\
\hline \multicolumn{5}{|l|}{ BMI in 1981} \\
\hline Model 1: All individuals, age and sex adjusted & 1.10 & $1.08,1.12$ & 1.07 & $1.06,1.09$ \\
\hline Model 2: All individuals, full covariate adjustment & 1.08 & $1.06,1.10$ & 1.06 & $1.04,1.07$ \\
\hline Model 3: All individuals, BMI in 1975, age and sex adjusted & 1.05 & $1.01,1.09$ & 1.04 & $1.02,1.07$ \\
\hline Model 4: All pairs & 1.03 & $0.98,1.08$ & 1.02 & $1.00,1.05$ \\
\hline Model 5: DZ pairs & 1.04 & $0.99,1.10$ & 1.02 & $0.99,10.6$ \\
\hline Model 6: MZ pairs & 0.96 & $0.85,1.09$ & 1.02 & $0.95,1.11$ \\
\hline
\end{tabular}

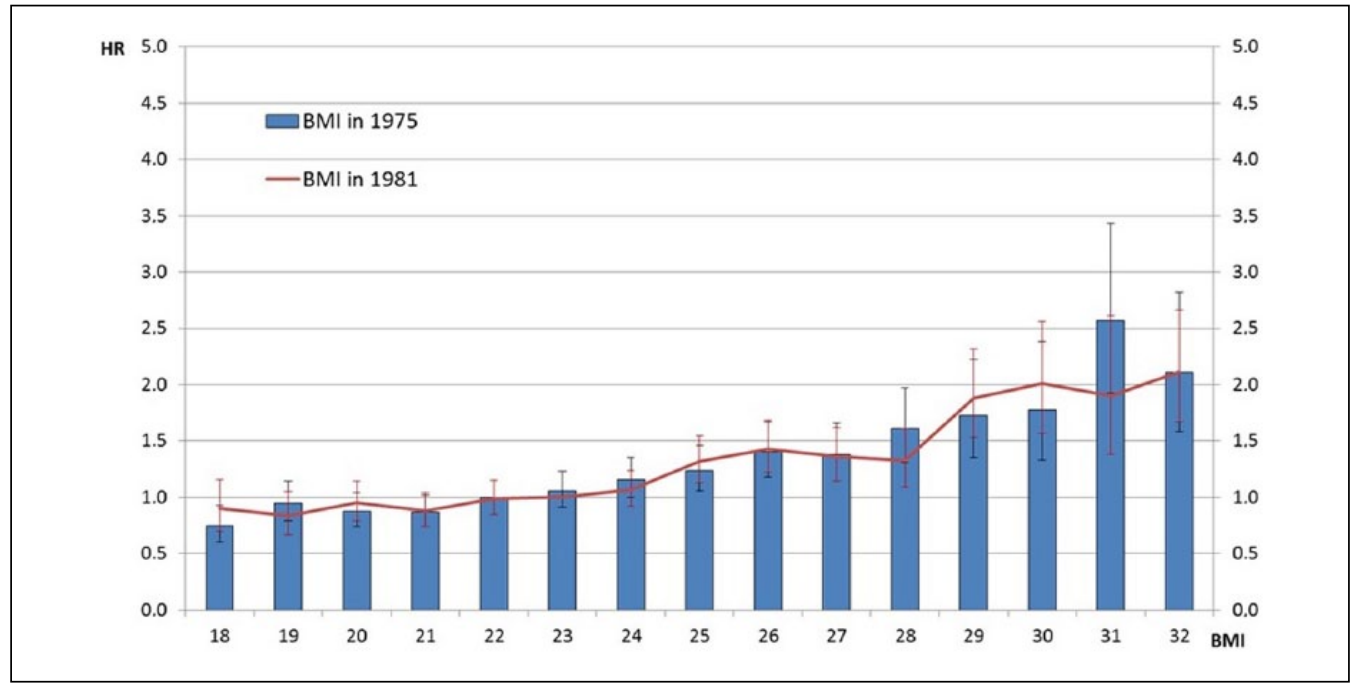

Figure 1. Age- and sex-adjusted hazard ratios for each value of BMI in 1975 and 1981 (reference values the means, respectively) predicting the risk for disability pension. Error bars indicate $95 \%$ CIs.

\section{Discussion}

Earlier studies have shown that BMI at one time point plays a role in the process of a person becoming incapable of working [4-11]. In addition, the few existing studies that have evaluated the change or stability of BMI over several time points have indicated a risk of temporary work incapacity $[5,12]$. This prospective cohort study may have been among the first to shed further light on the role of relative weight over two time points separated by six years in the risk of DP among over 17,000 twin individuals. In this study, each unit increase in BMI, and stable overweight and obesity, were both strong predictors of DP, but particularly for DP due to MSD over the 23-year follow-up.
Since this prospective dataset was collected from twins, we had the unique possibility to control, not only for the measured covariates that potentially influence both BMI and DP using a standard epidemiological analysis, but also for familial confounding through the use of co-twin control design. Thus, we took into account covariates such as marital status, education, socioeconomic status, leisure-time physical activity, and musculoskeletal pain locations, but also unknown or unmeasured factors shared by cotwins, including genetic background. The co-twin control design applies analyses of discordant twin pairs, and is a powerful tool, as individuals who differed in DP and BMI within a pair were also optimally matched cases and controls, as they were 


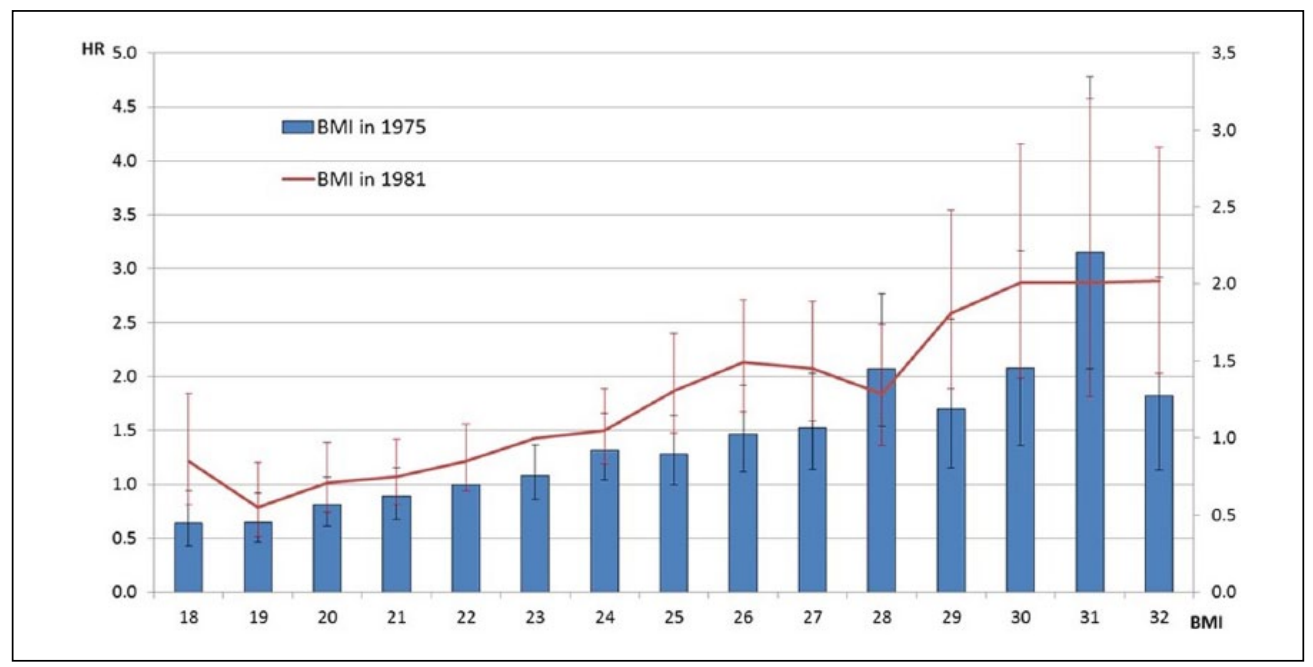

Figure 2. Age- and sex-adjusted hazard ratios for each value of BMI in 1975 and 1981 (reference values the means, respectively) predicting the risk for disability pension due to musculoskeletal diagnoses. Error bars indicate $95 \%$ CIs.

Table III. Cox proportional hazard ratios with $95 \%$ CIs of stability and change of BMI categories between 1975 and 1981 for those granted DP or DP due to MSD during the 23-year follow-up (1981-2004).

\begin{tabular}{|c|c|c|c|c|c|c|c|c|c|c|}
\hline \multirow[t]{2}{*}{ DP due to $\mathrm{MSD}^{\mathrm{a}}$} & \multicolumn{2}{|c|}{$\begin{array}{l}\text { Stable normal } \\
\text { weight }(n=514)\end{array}$} & \multicolumn{2}{|c|}{$\begin{array}{l}\text { Stable overweight } \\
(n=297)\end{array}$} & \multicolumn{2}{|c|}{$\begin{array}{l}\text { Stable obesity } \\
(n=57)\end{array}$} & \multicolumn{2}{|c|}{$\begin{array}{l}\text { Decreased BMI } \\
(n=76)\end{array}$} & \multicolumn{2}{|c|}{$\begin{array}{l}\text { Increased BMI } \\
(n=195)\end{array}$} \\
\hline & $\mathrm{HR}$ & $95 \% \mathrm{CI}$ & HR & $95 \% \mathrm{CI}$ & HR & $95 \% \mathrm{CI}$ & HR & $95 \% \mathrm{CI}$ & HR & $95 \% \mathrm{CI}$ \\
\hline $\begin{array}{l}\text { Model 1: All individuals, age } \\
\text { and sex adjusted }\end{array}$ & 1.00 & - & 1.62 & $1.39,1.89$ & 2.59 & $1.95,3.44$ & 1.66 & $1.40,1.96$ & 1.39 & $1.10,1.77$ \\
\hline $\begin{array}{l}\text { Model 2: All individuals, full } \\
\text { covariate adjustment }\end{array}$ & 1.00 & - & 1.44 & $1.22,1.68$ & 2.28 & $1.69,3.06$ & 1.51 & $1.27,1.80$ & 1.23 & $0.95,1.58$ \\
\hline Model 3: All pairs & 1.00 & - & 1.60 & $1.14,2.23$ & 2.35 & $1.14,4.83$ & 1.46 & $1.04,2.04$ & 1.43 & $0.89,2.31$ \\
\hline Model 4: DZ pairs & 1.00 & - & 1.65 & $1.14,2.39$ & 2.14 & $0.92,4.98$ & 1.70 & $1.16,2.49$ & 1.47 & $0.84,2.57$ \\
\hline Model 5: MZ pairs & 1.00 & - & 1.35 & $0.61,2.95$ & 2.40 & $0.57,10.10$ & 0.83 & $0.40,1.75$ & 1.19 & $0.46,3.09$ \\
\hline $\mathbf{D P a}$ & \multicolumn{2}{|c|}{$(n=1402)$} & \multicolumn{2}{|c|}{$(n=666)$} & \multicolumn{2}{|c|}{$(n=117)$} & \multicolumn{2}{|c|}{$(n=185)$} & \multicolumn{2}{|c|}{$(n=462)$} \\
\hline $\begin{array}{l}\text { Model 1: All individuals, age } \\
\text { and sex adjusted }\end{array}$ & 1.00 & - & 1.45 & $1.32,1.60$ & 2.19 & $1.80,2.66$ & 1.46 & $1.31,1.63$ & 1.27 & $1.09,1.47$ \\
\hline $\begin{array}{l}\text { Model 2: All individuals, full } \\
\text { covariate adjustment }\end{array}$ & 1.00 & - & 1.32 & $1.19,1.46$ & 1.91 & $1.56,2.34$ & 1.35 & $1.20,1.51$ & 1.18 & $1.01,1.38$ \\
\hline Model 3: All pairs & 1.00 & - & 1.23 & $1.00,1.52$ & 1.54 & $0.98,2.42$ & 1.27 & $1.03,1.58$ & 1.31 & $0.98,1.76$ \\
\hline Model 4: DZ pairs & 1.00 & - & 1.29 & $1.02,1.63$ & 1.55 & $0.92,2.60$ & 1.33 & $1.04,1.71$ & 1.39 & $0.98,1.96$ \\
\hline Model 5: MZ pairs & 1.00 & - & 1.02 & $0.64,1.64$ & 1.43 & $0.55,3.73$ & 1.06 & $0.68,1.66$ & 1.04 & $0.58,1.86$ \\
\hline
\end{tabular}

aThe number of individuals $(n)$ is given for the analyses of the whole cohort (models 1 and 2 ), whereas in the discordant pair analyses, the analyses were for the pairs (not shown in the table, models 3-5) and included $398 \mathrm{MZ}$ and $1075 \mathrm{DZ}$ pairs for DP, and $164 \mathrm{MZ}$ and 516 $\mathrm{DZ}$ pairs for DP due to MSD.

same-sexed twin pairs. The results suggest independence of the observed association from familial influences. Nevertheless, we cannot rule out the influence of familial influences due to attenuated point estimates among $M Z$ twins. However, the results mainly remained unchanged in both analyses for each unit of BMI and analyses for BMI categories over time, reflecting stability and change between 1975 and 1981. As the analyses may have lacked power, they should be interpreted with caution. This suggests that high relative weight has a potential direct effect on DP. These results are in line with earlier reports based on partially the same dataset [11], but also with a study on Swedish twins for decreased and increased BMI from 1973 to 1998-2003 [5], and a review evaluating studies of BMI and DP in 2008 [4]. Furthermore, an increase in BMI is strongly linked to an increase in age [1], and to the risk of DP [23]. We tried to capture this effect by investigating the interaction between BMI and age for DP, but a significant interaction was detected only among women with DP due to MSD. We found no interaction between BMI and sex while accounting for age. This suggests that either the interrelationship 
between BMI and age may play a minor role in predicting DP, or that this interrelationship should merit further studies with an even larger sample.

Since BMI is known to have a strong genetic component $[14,24]$ and DP is also moderately heritable $[15,17,25]$, it was considered possible that familial influences would play a role in the associations between BMI and future DP. However, familial factors had no effect on the associations between BMI and DP. This may suggest that unique environmental factors correlate between BMI and DP. Further, the results suggest a causal association between $\mathrm{BMI}$ and DP. However, more studies with even larger datasets are needed to confirm these findings, as we may have lacked power, particularly in the separate analyses of $\mathrm{MZ}$ and DZ twins. Alternatively, the putative causal association can be tested through Mendelian randomization analyses, which also typically require very large sample sizes due to the modest effect sizes associated with known genetic variants.

Our long follow-up, 23 years for DP, indicates that BMI during the early working career may be an early predictor of subsequent work incapacity. From a public health perspective, BMI is easy to measure and is usually assessed routinely in health check-ups. One potential pathway in the association between BMI and DP might be the mediating role of societal, work, and individual characteristics that may influence the risk of disease or accident, and the consequences of these, such as DP. Mediating factors may play a role in the decision to grant DP, i.e. severe obesity may complicate working in some occupations, consequently impairing the work capacity, or being underweight may prevent participation in social activities due to stigmatization and hence, lead to increased stress and work loading. Furthermore, the curvilinear association of BMI - i.e. both the extremes (underweight and severe obesity) - are linked with diseases, but also with work capacity [4], and, therefore, should be investigated and treated for any potential underlying medical condition to clarify the role in the process of the development of work incapacity. Hence, the results emphasize the societal costs of obesity as well as the costs for the obese individuals. High BMI or BMI that shows an increasing trend could trigger a more detailed evaluation of the individual's life situation, health behavior, and work capacity in an attempt to prevent work incapacity that could lead to DP. Across individual, organizational or societal levels, BMI would be a potential target for health promotion through tailored interventions due to the global pandemic of overweight and obesity [1].

This study has several strengths, including the use of longitudinal design with prospective follow-up from 1981 to 2004 , and nationally representative high quality registry data of DP with detailed diagnoses and dates. Furthermore, we had comprehensive survey data for a large cohort of Finnish twins, which permitted us to apply co-twin control design to control for familial confounding as well as a variety of other covariates. In addition, we were able to investigate BMI data from two time points separated by six years, enabling us to evaluate stability or change in BMI with the risk of permanent work incapacity. This has rarely been done before. However, we also need to address some limitations. BMI was based on self-reported weight and height, with known downward bias [26,27], although the validity of BMI values in this cohort was high [19]. This may have diluted the observed effect compared to objectively assessed BMI data, which may be hard to obtain in large samples with tens of thousands of individuals, as in this study. Despite the relatively large dataset with over 17,000 individuals, the power was not optimal for running the analyses for $\mathrm{MZ}$ and DZ twin pairs separately. Another potential limitation may lay in the specific welfare system and society of Finland. Therefore, the results may be applicable to other Nordic countries that have similar welfare models and societies, but somewhat less so to other countries. Furthermore, a limitation is that our follow-up was limited to the years between 1981 and 2004. It is obvious that the work life and occupational health care have changed during these 23 years. Therefore, this prospective design should be replicated with follow-up until more recent years to establish if the association between BMI and DP would be generalized to the current working life.

\section{Conclusions}

Relative weight in terms of BMI is an early and independent predictor for DP and DP due to MSD. BMI may possibly have a causal effect on the risk of DP, although the influence of genetic confounding merits further investigation.

\section{Conflict of interest}

None declared.

\section{Funding}

This work was supported by the Social Insurance Institution, Finland, for the TwinKela project, by the Academy of Finland's Center of Excellence in Complex Disease Genetics (grant numbers 213506 and 129680), Ministry of Education and Culture of Finland for AR and by the Academy of Finland (grant numbers 265240, 263278, 264146 and 266592) for the Finnish Twin Cohort studies. 


\section{References}

[1] $\mathrm{Ng} \mathrm{M}$, Fleming $\mathrm{T}$, Robinson $\mathrm{M}$, et al. Global, regional, and national prevalence of overweight and obesity in children and adults during 1980-2013: A systematic analysis for the Global Burden of Disease Study 2013. Lancet 2014;384:766-81.

[2] Lenz M, Richter T and Muhlhauser I. The morbidity and mortality associated with overweight and obesity in adulthood: A systematic review. Dtsch Arzteblt Int 2009;106:641-8.

[3] Dee A, Kearns K, O'Neill C, et al. The direct and indirect costs of both overweight and obesity: A systematic review. BMC Res Notes 2014;7:242.

[4] Neovius K, Johansson K, Rossner S, et al. Disability pension, employment and obesity status: A systematic review. Obesity Rev 2008;9:572-81.

[5] Ropponen A, Narusyte J, Alexanderson K, et al. Stability and change in health behaviours as predictors for disability pension: A prospective cohort study of Swedish twins. BMC Public Health 2011;11:68.

[6] Ropponen A, Silventoinen K, Tynelius P, et al. Association between hand grip/body weight ratio and disability pension due to musculoskeletal disorders: A population-based cohort study of 1 million Swedish men. Scand $\mathcal{F}$ Public Health 2011;39:830-8.

[7] Ropponen A and Svedberg P. Single and additive effects of health behaviours on the risk for disability pensions among Swedish twins. Eur f Public Health 2013;24:643-8.

[8] Samuelsson A, Ropponen A, Alexanderson K, et al. A prospective cohort study of disability pension due to mental diagnoses: The importance of health factors and behaviors. BMC Public Health 2013;13:621.

[9] Pietikäinen S, Silventoinen K, Svedberg P, et al. Healthrelated and sociodemographic risk factors for disability pension due to low back disorders: A 30-year prospective Finnish twin cohort study. F Occup Environ Med 2011;53:488-96.

[10] Roos E, Laaksonen M, Rahkonen O, et al. Relative weight and disability retirement: A prospective cohort study. Scand FWork Environ Health 2013;39:259-67.

[11] Ropponen A, Silventoinen K, Svedberg P, et al. Healthrelated risk factors for disability pensions due to musculoskeletal diagnoses: A 30-year Finnish twin cohort study. Scand F Public Health 2011;39:839-48.

[12] Roos E, Laaksonen $M$, Rahkonen $\mathrm{O}$, et al. Weight change and sickness absence-A prospective study among middleaged employees. Eur f Public Health 2015;25:263-7.

[13] Neovius M, Kark M and Rasmussen F. Association between obesity status in young adulthood and disability pension. Int f Obes 2008;32:1319-26.
[14] Min J, Chiu DT and Wang Y. Variation in the heritability of body mass index based on diverse twin studies: A systematic review. Obes Rev 2013;14:871-82.

[15] Harkonmäki K, Silventoinen K, Levälahti E, et al. The genetic liability to disability retirement: A 30-year follow-up study of 24,000 Finnish twins. PLoS ONE 2008;3:e3402.

[16] Narusyte J, Ropponen A, Alexanderson K, et al. The role of familial factors in the associations between sickness absence and disability pension or mortality. Eur $\mathcal{f}$ Public Health 2014;24:106-10.

[17] Gjerde LC, Knudsen GP, Czajkowski N, et al. Genetic and environmental contributions to long-term sick leave and disability pension: A population-based study of young adult Norwegian twins. Twin Res Hum Genet 2013;16:759-66.

[18] Kaprio J and Koskenvuo M. Genetic and environmental factors in complex diseases: The older Finnish twin cohort. Twin Res 2002;5:358-65.

[19] Korkeila M, Kaprio J, Rissanen A, et al. Predictors of major weight gain in adult Finns: Stress, life satisfaction and personality traits. Int $\mathcal{F}$ Obes Relat Metab Disord 1998;22: 949-57.

[20] Kujala UM, Kaprio J, Sarna S, et al. Relationship of leisure-time physical activity and mortality: The Finnish twin cohort. FAMA 1998;279:440-4.

[21] Williams RL. A note on robust variance estimation for cluster-correlated data. Biometrics 2000;56:645-6.

[22] Ropponen A, Svedberg P, Kalso E, et al. A prospective twin cohort study of disability pensions due to musculoskeletal diagnoses in relation to stability and change in pain. Pain 2013;154:1966-72.

[23] Allebeck P and Mastekaasa A. Swedish Council on Technology Assessment in Health Care (SBU). Chapter 5. Risk factors for sick leave-General studies. Scand $\mathcal{F}$ Public Health 2004;32:49-108.

[24] Elks CE, den Hoed M, Zhao JH, et al.Variability in the heritability of body mass index: A systematic review and metaregression. Front Endocrinol 2012;3:29.

[25] Narusyte J, Ropponen A, Silventoinen K, et al. Genetic liability to disability pension in women and men: A prospective population-based twin study. PLoS ONE 2011;6:e23143.

[26] Ezzati M, Martin H, Skjold S, et al. Trends in national and state-level obesity in the USA after correction for selfreport bias: Analysis of health surveys. $\mathcal{F} R$ Soc Med 2006;99: 250-7.

[27] Krul AJ, Daanen HA and Choi H. Self-reported and measured weight, height and body mass index (BMI) in Italy, the Netherlands and North America. Eur $\mathcal{F}$ Public Health 2011;21:414-9. 